Article

\title{
Impact of Self-Cleansing Criteria Choice on the Optimal Design of Sewer Networks in South America
}

\author{
Carlos Montes ${ }^{1}$, Zoran Kapelan ${ }^{2}$ and Juan Saldarriaga ${ }^{3, *}$ \\ 1 Water Supply and Sewer Systems Research Center (CIACUA), Universidad de los Andes, \\ Bogotá 111711, Colombia; cd.montes1256@uniandes.edu.co \\ 2 Faculty of Civil Engineering and Geosciences, Delft University of Technology, 2600 AA Delft, The Netherlands; \\ Z.Kapelan@tudelft.nl \\ 3 Department of Civil and Environmental Engineering, Universidad de los Andes, Bogotá 111711, Colombia \\ * Correspondence: jsaldarr@uniandes.edu.co; Tel.: +57-1-339-49-49 (ext. 3282)
}

Received: 20 February 2019; Accepted: 10 April 2019; Published: 31 May 2019

check for updates

\begin{abstract}
This paper aims to analyze different sediment self-cleansing criteria and to find out what the corresponding implications are on the optimal design of sewer systems. A methodology based on enumeration is used to find the sewer network design that minimizes the costs of construction while fulfilling a number of design criteria including self-cleansing constraints. Three stormwater and wastewater sewer networks are used for the analyses. The results indicate that in cases where the terrain slopes and design flow rates are higher, the self-cleansing restrictions are irrelevant to the optimal design. However, when the terrain slopes and the design flow rates are lower, these restrictions affect the final design. Using the results obtained, a graph is constructed showing the limit at which self-cleansing restrictions become a constraining parameter in optimal design for sewer networks. It is expected that this graph will be useful for the design of future sewer networks in low-income areas, where the design of traditional, gravity-based sewer systems is essential.
\end{abstract}

Keywords: self-cleansing sewer systems; self-cleansing criteria; sewer system optimal design; sedimentation

\section{Introduction}

Sewer systems can be defined as an infrastructure used to collect and transport stormwater and wastewater produced in urban areas. Traditionally, these systems have been designed without considering optimization criteria, which has resulted in high construction costs and overdesigned sewer networks. Recently, several techniques have been proposed to reduce construction costs. These techniques include typical recommendations and constraints proposed in several water utilities design manuals. Some of these constraints include minimum velocities or minimum shear stress values to guarantee self-cleansing conditions in sewer systems.

The traditional design of sewer networks has been considered to be a single-objective strategy, i.e., without including construction costs. Recently, several authors have used multi-objective strategies, which consider an optimal design of sewer pipes while a cost function equation is being minimized. Techniques such as dynamic programming [1,2], nonlinear programming [3], random search [4], LP-based heuristic approach [5], genetic algorithms [6-10], automated algorithm combining hydraulic and hydrological simulation [11], and DP-based optimization engine [12], amongst other approaches, have been used for the optimal design of sewer systems. Each of these approaches has been used in several benchmark sewer networks, e.g., Mays and Wenzel [13] stormwater sewer network, taking into account different cost function equations and design constraints. 
Part of the design constraints included in water utilities design manuals relate to self-cleansing capacity. In this context, the concept of self-cleansing sewer systems has been introduced in sanitary engineering practices. These systems must guarantee that transported particles do not deposit at the bottom of the pipes, avoiding problems such as changes in the pipe cross-section or variations in the water velocity profiles [14]. Some phenomena associated with these problems include blockages, overcharges, water quality, and flooding.

In order to prevent problems such as the previously stated ones, several minimum velocities, and minimum shear stress values have been proposed in the design manuals of different countries. Usually, self-cleansing criteria depends on the type of sewer, i.e., stormwater, wastewater or combined sewer system, and sometimes on the pipe's diameter, e.g., Germany [15]. On the basis of this criteria, Table 1 summarizes traditional values of self-cleansing criteria, obtained from the previous studies of Vongvisessomjai et al. [16] and complemented with self-cleansing criteria collected in the United States, Europe, and Latin American water utilities [17]. These values have traditionally been used in the design of small sewer networks [16] and are widely employed today.

Table 1. Minimum velocity and shear stress values.

\begin{tabular}{|c|c|c|c|c|c|}
\hline Criterion No. & Source & Country & Sewer Type & $v_{\min }[\mathrm{m} / \mathrm{s}]$ & $\tau_{\min }[\mathrm{Pa}]$ \\
\hline (1) & Lysne [18] & USA & All & - & $2.0-4.0$ \\
\hline \multirow[t]{2}{*}{ (2) } & \multirow{2}{*}{ ASCE [19] } & \multirow{2}{*}{ USA } & WW & 0.6 & - \\
\hline & & & SW & 0.9 & - \\
\hline \multirow{2}{*}{ (3) } & \multirow{2}{*}{ Yao [20] } & \multirow{2}{*}{ USA } & SW & - & $3.0-4.0$ \\
\hline & & & WW & - & $1.0-2.0$ \\
\hline \multirow{2}{*}{ (4) } & \multirow{2}{*}{ Minister of Interior [21] } & \multirow{2}{*}{ France } & WW & 0.3 & - \\
\hline & & & C & 0.6 & - \\
\hline \multirow{2}{*}{ (5) } & \multirow{2}{*}{ British Standard BS 8001 [22] } & \multirow{2}{*}{ UK } & SW & 0.75 & - \\
\hline & & & $\mathrm{C}$ & 1 & - \\
\hline \multirow{2}{*}{ (6) } & \multirow{2}{*}{$\begin{array}{c}\text { Ecuadorian Normalization Institute (Instituto Ecuatoriano de } \\
\text { Normalización) [23] }\end{array}$} & \multirow{2}{*}{ Ecuador } & WW & 0.45 & - \\
\hline & & & SW & 0.9 & - \\
\hline (7) & European Standard EN 752-4 [24] & Europe & All & 0.7 & - \\
\hline (8) & ATV-DVWK-Regelwerk [15] & Germany & All & Depends on pipe diameter & - \\
\hline (9) & Great Lakes [25] & USA & WW & 0.6 & - \\
\hline \multirow{2}{*}{ (10) } & \multirow{2}{*}{ National Water Commission (Comisión Nacional del Agua) [26] } & \multirow{2}{*}{ Mexico } & SW & 0.6 & - \\
\hline & & & WW & 0.3 & - \\
\hline \multirow[t]{2}{*}{ (11) } & \multirow{2}{*}{$\begin{array}{c}\text { Bolivian Institute for Standarization and Quality (Instituto } \\
\text { Boliviano de Normalización y Calidad) [27] }\end{array}$} & \multirow{2}{*}{ Bolivia } & WW & - & 1 \\
\hline & & & SW and C & - & 1.5 \\
\hline (12) & Medellin Public Enterprises (Empresas Públicas de Medellín) [28] & \multirow{2}{*}{ Colombia } & WW & 0.45 & 1.5 \\
\hline \multirow{2}{*}{ (13) } & \multirow{2}{*}{$\begin{array}{c}\text { Colombia. Ministry of Housing, City and Territory (Colombia. } \\
\text { Ministerio de Vivienda, Ciudad y Territorio) [29] }\end{array}$} & & SW and C & 0.75 & 3 \\
\hline & & Colombia & SW and C & $\begin{array}{l}0.45 \\
0.75\end{array}$ & $\begin{array}{c}1.5 \\
3\end{array}$ \\
\hline
\end{tabular}

Note: WW, wastewater; SW, stormwater; C, combined; All, all sewers.

The self-cleansing criteria, shown above, are commonly used to avoid the problems aforementioned. In addition, the criteria shown in Table 1 cover the range of variation found in water utilities design manuals. These values vary in different manuals and regions because of different climate conditions, lifestyles, and cultures of people. These variations in self-cleansing criteria have usually been discussed by water utilities, since there is no agreement that establishes a definitive or permanent self-cleansing criterion. On the basis of previous concepts, this paper aims to evaluate the impact of different self-cleansing criteria, as shown in Table 1, on the optimal design of sewer networks. This evaluation is important, especially in low-income areas of South America, where the design of gravity-based sewer systems is essential, and the implementation of non-traditional systems, i.e., systems that consider pump infrastructure, is usually not possible. In this context, a preliminary assessment of the impact of self-cleansing criteria, especially in flat areas with low population density, on the design of future sewer networks is essential to the evaluation of the feasibility of implementing a sewer system. In areas where this is not possible, other solutions should be implemented, such as condominial sewer systems or septic tanks, among others.

The remainder of the paper is organized as follows: Section 2 presents the methodology used for the optimal design of sewer systems, the cost function, the hydraulic design constraints, and case studies. Section 3 contains the solution of each network and the preliminary results. Section 4 presents a sensitivity analysis which is performed to establish the limits of the terrain slope and design flow where self-cleaning criteria affect the final optimized network design. Section 5 outlines the conclusions. 


\section{Methodology}

\subsection{Optimal Sewer Network Design}

\subsubsection{Design Cost}

The sewer design methodology used in this study is described by Duque et al. [12]. It is a three-step approach, based on graph modeling and shortest path algorithm, which is solved using the Bellman-Ford algorithm [30]. In this approach, an exhaustive search is used to find the best combination of slope and diameter for each pipe in a sewer network. The best combination chosen guarantees a minimum total cost of the network, represented by Equation (1), fulfilling the design constraints shown in Table 2.

Table 2. Hydraulic design constraints modified from Duque et al. [12].

\begin{tabular}{cc}
\hline Design Constraint & Threshold Value \\
\hline Minimum diameter & $200 \mathrm{~mm}$ \\
Maximum filling ratio & 0.85 \\
Minimum self-cleansing velocity & $0.6-0.9 \mathrm{~m} / \mathrm{s}$ \\
Minimum shear stress & $2.0-4.0 \mathrm{~Pa}$ \\
Maximum velocity & $5.0 \mathrm{~m} / \mathrm{s}$ \\
Minimum depth below ground level & $1.2 \mathrm{~m}$ \\
Maximum depth below ground level & $5.0 \mathrm{~m}$ \\
\hline
\end{tabular}

In this methodology, each graph is considered as a combination of nodes (manholes) and arcs (pipes), representing a single sewer design with a specific cost and a combination of diameter and slope of each pipe. In addition, each manhole is represented by a subset of elevation and diameter. On the basis of this information, each pipe in the network is created by joining two consecutive manholes with a specific upstream and downstream elevation, i.e., with a specific slope and diameter. The subset of diameters depends on the commercially available diameters.

The methodology has been tested for several sizes of networks, varying the number of pipes from 5 to 20. According to Duque et al. [12], the number of pipes and the terrain topography (steep or flat terrain) affect the computational time. As an example, the computational time required to solve a network with five pipes located in a flat topography is close to $45 \mathrm{~s}$; in contrast, the computational time required to solve a network with 20 pipes located in a steep topography is about $190 \mathrm{~s}$. As previously mentioned, this methodology allows for the design of sewer networks in a short time. The full details of this methodology are outlined by Duque et al. [12].

The total cost function used for the analyses is a regression-based cost model, developed using data from different sources such as the Ministry of Environment (Colombia), the Housing and Territorial Development (Ministerio de Ambiente, Vivienda y Desarrollo Territorial, in Spanish), the Financial Fund for Development Projects (Fondo Financiero de Proyectos de Desarrollo FONADE, in Spanish), and from sewage and water utilities. Equation (1) presents the cost function where $C$ represents the total cost (USD), $D$ is the pipe diameter (mm), $l$ is the pipe length $(\mathrm{m})$ and $V$ is the excavated volume $\left(\mathrm{m}^{3}\right)$, as defined in Equation (2).

$$
\begin{gathered}
C=\frac{1.32}{2,800}\left(9579 D^{0.57} l+1163 V^{1.31}\right) \\
V=\left(D+2 e+0.15+\frac{H+H^{\prime}}{2}\right) \times(2 B+2 e+D) \times\left(l \cos \left(\tan ^{-1} S_{o}\right)\right)
\end{gathered}
$$

where $e$ is the wall thickness of the pipe $(\mathrm{m}) ; H$ and $H^{\prime}$ are the excavation limits above the top of the pipe in the upstream and downstream of the pipe $(\mathrm{m})$, respectively; $B$ is the width of trench $(\mathrm{m})$; and $S_{o}$ is the pipe slope $(\mathrm{m} / \mathrm{m})$. 
The cost equation shown above is deemed appropriate for the work done here with this methodology. This equation is useful for analyses, especially in South America, because it was developed using information available in the region. However, the methodology presented in this paper is generic in the sense that it allows alternative cost model(s) equations to be used, e.g., Maurer et al. [31], Moeini and Afshar [32] and Marchionni et al. [33], amongst others.

\subsubsection{Design Constraints}

Several design constraints are considered to ensure proper operation of sewer systems. These constraints are usually recommended by the technical standards of each water utility. This study takes the following restrictions suggested by the Colombian Standard [29]:

1. Minimum pipe diameter required for the cleaning and maintenance of the network;

2. Maximum filling ratio that must be enabled to allow adequate aeration in the system;

3. Minimum velocity and shear stress inside the pipes necessary to prevent particle sedimentation;

4. Maximum velocity required to prevent problems such as cavitation and pipe wall erosion;

5. Minimum and maximum depth below ground level necessary to protect the pipe structure from overloading and axial stresses, respectively.

\subsection{Self-Cleansing Limits}

The limits of self-cleansing are obtained by solving the Manning equation, for circular conduits, for a specific minimum self-cleansing velocity and pipe diameter, according to Equation (3). The self-cleansing limit for minimum shear stress is estimated by solving the shear stress equation for a shear stress value and pipe diameter, according to Equation (4). Using these equations, it is possible to estimate the minimum self-cleansing slope based on a specific self-cleansing criterion of minimum velocity or minimum shear stress, and considering several pipe diameters and filling ratios:

$$
\begin{aligned}
v_{l} & =\frac{1}{n}\left[\frac{D\left(\pi+2 \sin ^{-1}\left(\frac{2 y}{D}-1\right)-\sin \left(\pi+2 \sin ^{-1}\left(\frac{2 y}{D}-1\right)\right)\right)}{4\left(\pi+2 \sin ^{-1}\left(\frac{2 y}{D}-1\right)\right)}\right]^{2 / 3} S_{\text {min }}^{1 / 2} \\
\tau & =\gamma\left[\frac{D\left(\pi+2 \sin ^{-1}\left(\frac{2 y}{D}-1\right)-\sin \left(\pi+2 \sin ^{-1}\left(\frac{2 y}{D}-1\right)\right)\right)}{4\left(\pi+2 \sin ^{-1}\left(\frac{2 y}{D}-1\right)\right)}\right] S_{\text {min }}
\end{aligned}
$$

where $S_{\min }$ is the minimum self-cleansing pipe slope, $v_{l}$ is the minimum self-cleansing velocity constraint, $n$ is the Manning's roughness coefficient equal to $0.013 \mathrm{~m}^{-1 / 3} \mathrm{~s}$ for all the conduits of the sewer network, $y$ is the water depth, $D$ is the pipe diameter, $\tau$ is the minimum shear stress value constraint, and $\gamma$ is the specific weight of water.

\section{Case Studies}

\subsection{Description}

Three different sewer networks are used to test the impact of self-cleansing criteria in sewer systems.

The first network is a stormwater system that is part of the Bogota's, Colombia, full network, located in an area named Chicó. This network includes 36 nodes and 35 pipes, as shown in Figure 1A. Table S1, which can be found in the Supplementary Material, shows the ground elevation and design flow for each pipe in the analyzed network.

The second network used for the analysis is proposed by Mays and Wenzel [13]. This stormwater sewer network consists of 20 pipes and 21 nodes with the layout shown in Figure 1B. The ground elevation and design flow rate data can be found in Table S2, in the Supplementary Material. 
The last network is the Kerman city wastewater network in Iran which has been reported in many studies [10,34]. This network includes 20 pipes and 21 nodes, as shown in Figure 1C. Table S3, in the Supplementary Material, shows the ground elevation and the design flow rate of each pipe in this network.
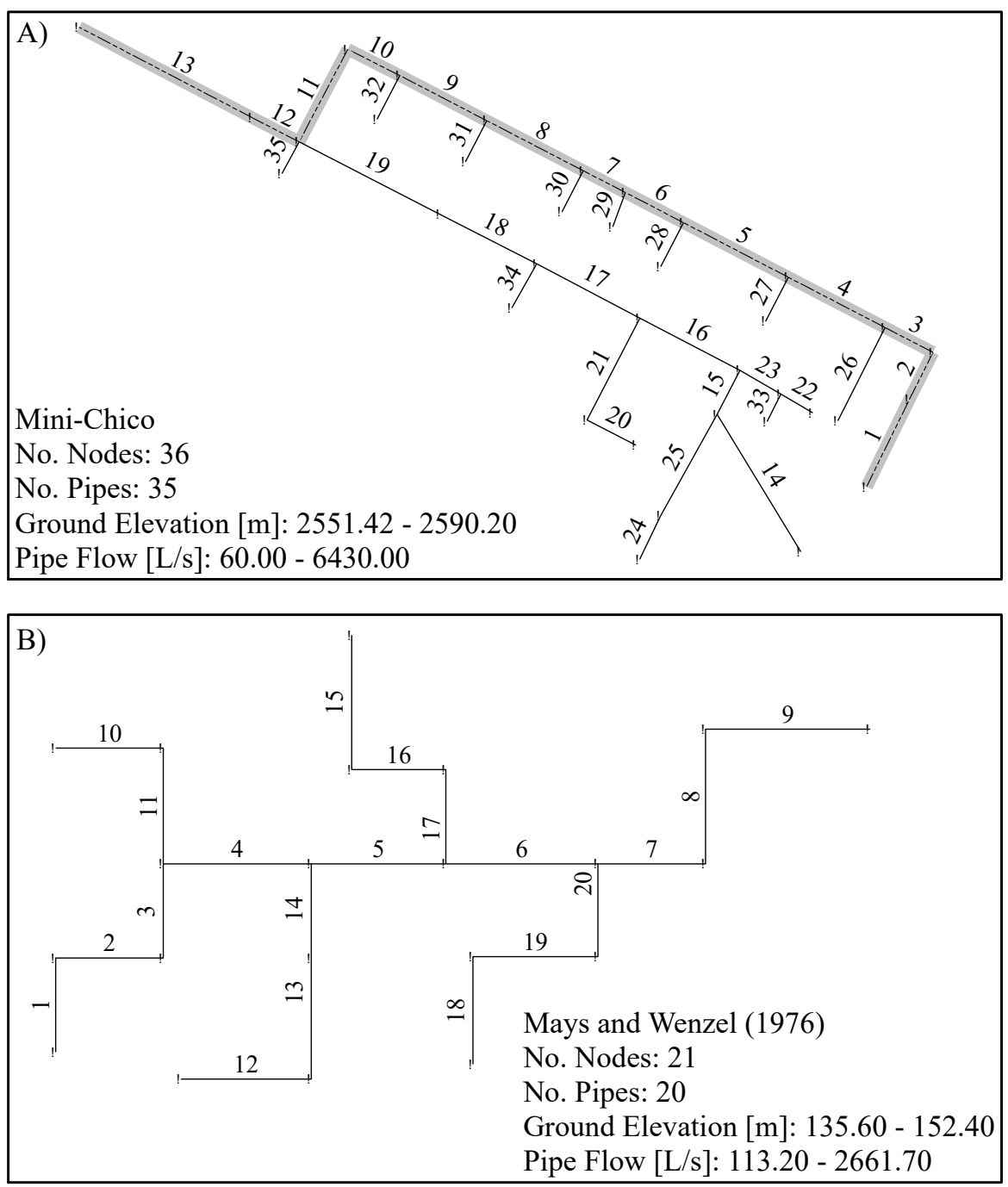

C)

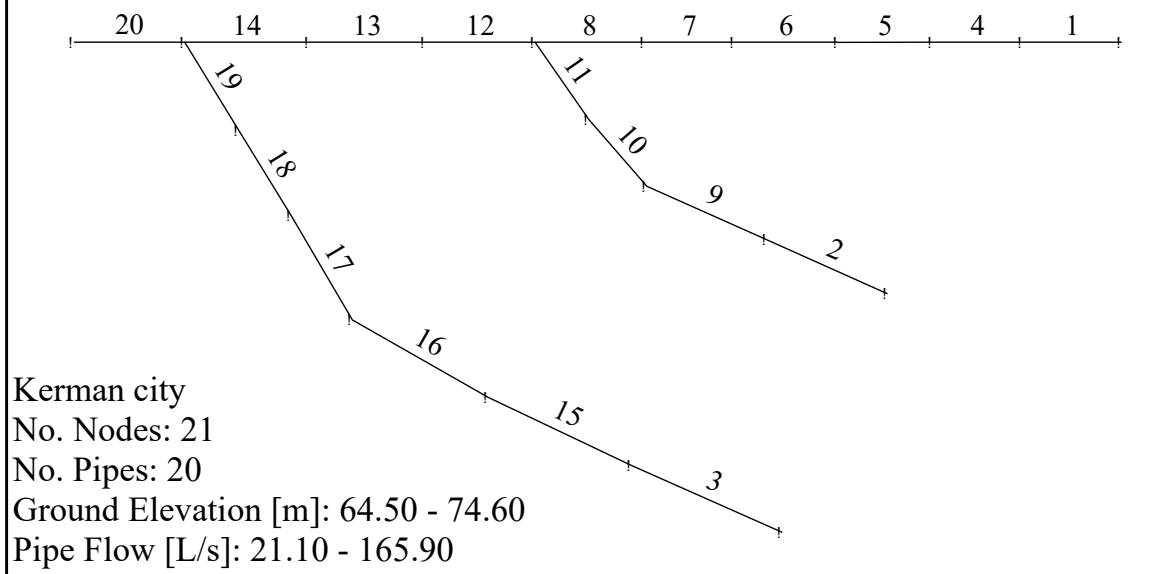

Figure 1. Sewer networks used for the analyses: (A) Mini-Chicó network; (B) Mays and Wenzel [13] network and (C) Kerman city network. 


\subsection{Design Constraints}

Each network is designed considering the constraints shown in Table 2 and using the optimal design methodology proposed by Duque et al. [12]. As Table 2 shows, the minimum self-cleansing velocity and minimum shear stress constraints are presented as a range since they depend on the value (criterion) chosen in Table 1. Likewise, pipe diameters of 200, 250, 300, 350, 380, 400, 450, 500, 530, 600, $700,800,900,1000,1050,1200,1350,1400,1500,1800,2200,2500,2800$, and $3000 \mathrm{~mm}$ are assumed available for those sewer network designs.

The values of all constraint variables are presented in Table 2. These values are used in the optimization methodology presented here. As in the case of a cost model, the methodology presented here is generic in the sense that other constraints used by different water utilities can be used instead.

A number of self-cleansing criteria are used in three case studies, these are shown as follows (see Table 1): (1), (3), (6), (10), and (13). The chosen criteria, cover a range of variation of the minimum velocity and minimum shear stress criteria applied to stormwater sewer systems, established by water utilities in the USA, Europe, and Latin America, i.e., minimum velocity $=(0.60-0.90) \mathrm{m} / \mathrm{s}$ and shear stress $=(2.0-4.0) \mathrm{Pa}$.

\section{Self-Cleansing Limits}

Equations (3) and (4) are used to estimate the impact of several self-cleansing criteria on the design of sewer networks. A simple general step-by-step procedure to obtain the self-cleansing limits is considered as follows:

1. Select a minimum velocity or minimum shear stress from Table 1;

2. Select a pipe diameter;

3. Define the filling ratio $\frac{y}{D}$;

4. Solve Equation (3), for the minimum velocity, or Equation (4), for shear stress, to estimate the minimum self-cleansing slope;

5. Move to the next pipe diameter and repeat step 4;

6. Move to the next self-cleansing criterion in Table 1 and start the entire procedure over again.

By applying the previous step-by-step procedure, it is possible to obtain several self-cleansing thresholds for each criterion. These results can be seen in the lines of Figure 2.
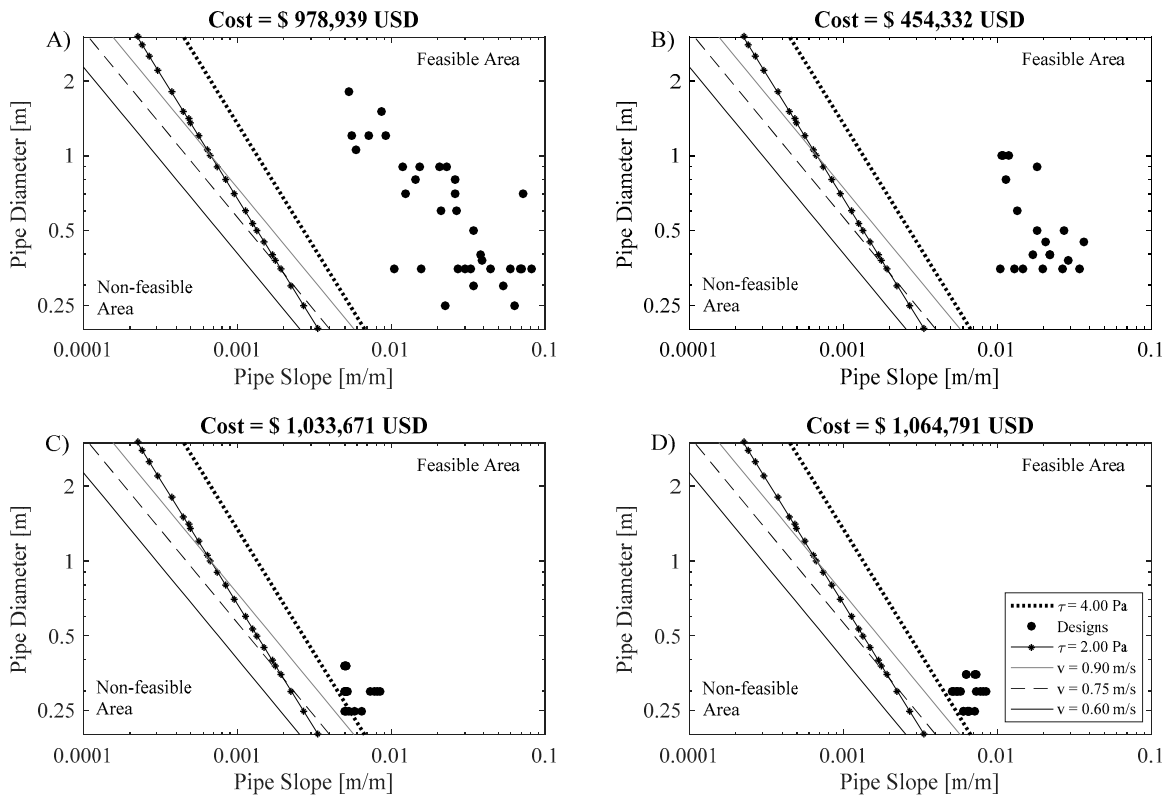

Figure 2. Design results and total costs for the three networks: (A) Mini-Chicó, (B) Mays and Wenzel [13], (C) Kerman city Design I, and (D) Kerman city Design II. 


\subsection{Design Procedure}

The procedure for designing sewer networks using Duque et al. [12] methodology is as follows:

1. Create a .txt file that includes the manholes of the main path of the network. Each manhole must include ground elevation and inflow information;

2. Define design constraints and list of available commercial diameters;

3. Create a graph with all the possible arcs (pipes). Each arc has an associated pipe diameter as well as upstream and downstream elevation to calculate the slope;

4. Calculate the cost of each pipe using Equation (1);

5. Calculate the hydraulic of each arc, i.e., determine flow, hydraulic radius, wetted area, and top width, amongst other hydraulic parameters, using the Manning equation using Equation (3). If the arc does not fulfill all the design constraints it will not be created;

6. Use the Bellman-Ford algorithm to estimate the combination of arcs that minimize network cost;

7. Report the results of the slope and diameter of each pipe in the network.

The previous procedure is applied to each network in Figure 1. The results of the best combination of slope versus pipe diameter for each consecutive manhole are presented as dots in Figure 2.

\section{Results and Discussion}

The optimal designs for three sewer networks are presented in Figure 2. These designs compare and analysis the influence of different self-cleansing criteria on the final cost of the networks. Figure 2 shows the threshold (i.e., the line) for each self-cleansing criterion considered. Each threshold represents the minimum self-cleansing slope $\left(S_{o}\right.$ in Equations (3) and (4)) for each commercially available diameter. In addition, Figure 2 shows that the minimum self-cleansing velocity criteria tends to be less restrictive for large diameters $(D>1.0 \mathrm{~m})$. As well, the minimum shear stress of $4.0 \mathrm{~Pa}$ is clearly more restrictive than the minimum self-cleansing velocities. In contrast, the minimum shear stress of $2.0 \mathrm{~Pa}$ tends to be less restrictive than the minimum self-cleansing velocities in small sewers $(D<1.0 \mathrm{~m})$. The threshold line for a shear stress value of 2.0 Pa intersects the minimum velocities thresholds of $0.9 \mathrm{~m} / \mathrm{s}$ and $0.75 \mathrm{~m} / \mathrm{s}$ close to diameters of $1.0 \mathrm{~m}$ and $0.45 \mathrm{~m}$, respectively. These intersections are produced by the nature of the equations used to calculate the minimum self-cleansing slope, according to Equations (3) and (4).

As seen in Figure 2, the results (i.e., each dot in Figure 2 shows the best combination of slope vs diameter of each pipe in the network, estimated by the methodology used) of the Mini-Chico and Mays and Wenzel [13] networks (Figure 2A,B), which are stormwater sewer networks, show that self-cleansing restrictions are not a critical parameter in the optimal design of these systems, since all points (i.e., network pipes) are located in the feasible area (i.e., region of graph where all the possible combinations of diameter and slope of each pipe fulfills the self-cleansing criteria). In this case, the final cost is the same for all the self-cleansing restrictions.

However, in the case of the Kerman city network designs (Figure 2C,D), the self-cleansing restrictions have an impact on the final design of the network. As a result, two different designs are obtained: first, for the minimum velocities/shear stresses of $0.6 \mathrm{~m} / \mathrm{s}, 0.75 \mathrm{~m} / \mathrm{s}, 0.9 \mathrm{~m} / \mathrm{s}$, and $2.0 \mathrm{~Pa}$ (Figure 2C); and second, for the minimum shear stress of 4.0 Pa (Figure 2D). The final cost of the network is calculated using Equation (1) and increases when a self-cleansing restriction of 4.0 Pa is used. This means that the diameter or the slope of the pipes increases, as compared with designs obtained with the least restrictive criteria, to satisfy the hydraulic constraints. On the basis of previously mentioned information, it is possible to conclude that the final optimal design of a wastewater sewer network, i.e., networks with low inflows per node, depends on the self-cleansing criterion used in the design.

The results in Figure 2 show a relationship between the design flow of the pipes, the ground elevation (or terrain slope), and the self-cleansing criteria. In networks with high flow rates and highly variable ground elevation, such as the Mini-Chicó and Mays and Wenzel [13] stormwater networks (Figure 2B), pipe designs are always above the self-cleansing restrictions limit, or in the feasible area, 
when highly self-cleansing constraining criteria such as $4.0 \mathrm{~Pa}$ are used. However, networks with low flow rates and little topographic difference, such as the wastewater Kerman city network, are affected by the self-cleansing restriction, and costs will be higher when the criteria are more restrictive.

The above analysis of the results of the case studies made it necessary to perform a sensitivity analysis on the design of the network, with the objective to identify limit flow rates and limit terrain slopes. This sensitivity analysis seeks to evaluate scenarios with low flow rates (wastewater sewer networks) and low ground elevation differences to determine the relevance of self-cleansing criteria under these circumstances.

\section{Sensitivity Analysis}

On the basis of the results of the previous section, a sensitivity analysis is performed considering only the main path of the Mini-Chicó network, i.e., the highlighted path shown in Figure 1A. The ground elevation and the inflow rate of each node in this path are modified. It is carried out to find the limit where self-cleansing criteria, even highly constraining criteria, does not change the final cost of the optimal sewer network design. This analysis is performed for wastewater sewer system conditions only, since the purpose is to assess the behavior of low design flow rates under different topographic conditions.

In the context of this information, five simulations, where different combinations of flow rates and terrain topography, i.e., ground elevation, are analyzed. For each simulation, a constant inflow and a variable ground elevation in each node of the main path of the Mini-Chicó network are assumed. For example, in the first scenario of the first simulation, each node has a constant inflow of $1 \mathrm{~L} / \mathrm{s}$, and its ground elevation does not change, compared to the original ground elevation of the network. Accordingly, pipe one of the path will have a design flow rate of $1 \mathrm{~L} / \mathrm{s}$ and a ground elevation of $2587.34 \mathrm{~m}$ and $2575.50 \mathrm{~m}$ at the upstream and downstream nodes, respectively (as shown in Table S4, in the Supplementary Material). Following this idea, pipe two will have a design flow of $2 \mathrm{~L} / \mathrm{s}$ and a ground elevation of $2575.50 \mathrm{~m}$ and $2569.69 \mathrm{~m}$ in the upstream and downstream node, respectively, and this is repeated until the last pipe is reached. Another example is the second scenario of the first simulation, where the ground elevation is $50 \%$ of the original conditions. In this case, the ground elevation of each node of the path is multiplied by 0.5 and the design flow is the same as compared to case one of the first scenario, which means the first pipe now has a ground elevation of $1293.67 \mathrm{~m}$ for the upstream node and $1287.75 \mathrm{~m}$ for the downstream node. The five proposed simulations are presented in the Supplementary Material, Tables S4-S8.

The proposed methodology is applied to the defined scenarios. This methodology takes into account the self-cleansing criteria (3), (4), (6), (9), (11), and (12) shown in Table 1, which are used for wastewater sewer systems, and it covers the range of self-cleansing criteria for variations of these systems. The results of the methodology for each simulation are presented in Figure 3.

For the wastewater sewer system case, it is found that as slopes decrease, network costs vary depending on the self-cleansing criteria considered. This suggests that the optimal design is not independent of self-cleansing criteria. In scenario one of the first simulation, where the terrain slopes are relatively high, i.e., greater than $1.8 \%$, as shown in Figure $3 \mathrm{~A}$, sewer design costs are independent of self-cleansing criteria because there is no variation on the cost for the considered criteria. However, for other scenarios of the same simulation, as slopes decrease, e.g., scenario 3 (terrain slope of $0.53 \%$ ) to scenario 5 (terrain slope of $0.09 \%$ ), the network costs variability becomes larger, depending on the self-cleansing criteria considered.

On the basis of the results, it is possible to propose a power regression between mean terrain slope and the inflow per node. The purpose of this regression is to establish the limit conditions on which costs change as a function of self-cleansing restrictions for sewer system designs. Figure 4 presents the relationship between inflow per node and terrain slope in the main path of the analyzed network. The horizontal axis represents the mean terrain slope, while the vertical axis represents the inflow per node in the network. As a result, the dots in Figure 4 indicate the combination of terrain slope and inflow per node in which self-cleansing criteria do not modify the final cost of 
the network. Consequently, designing with a criterion of $0.6 \mathrm{~m} / \mathrm{s}$ for minimum velocity, or $2.0 \mathrm{~Pa}$ for minimum shear stress, is irrelevant. The potential regression curve is generated using the dots described previously. It is found that the self-cleansing threshold can be estimated with the equation, inflow per node $=0.0615 \times$ terrain slope $\mathrm{e}^{-0.718}$.
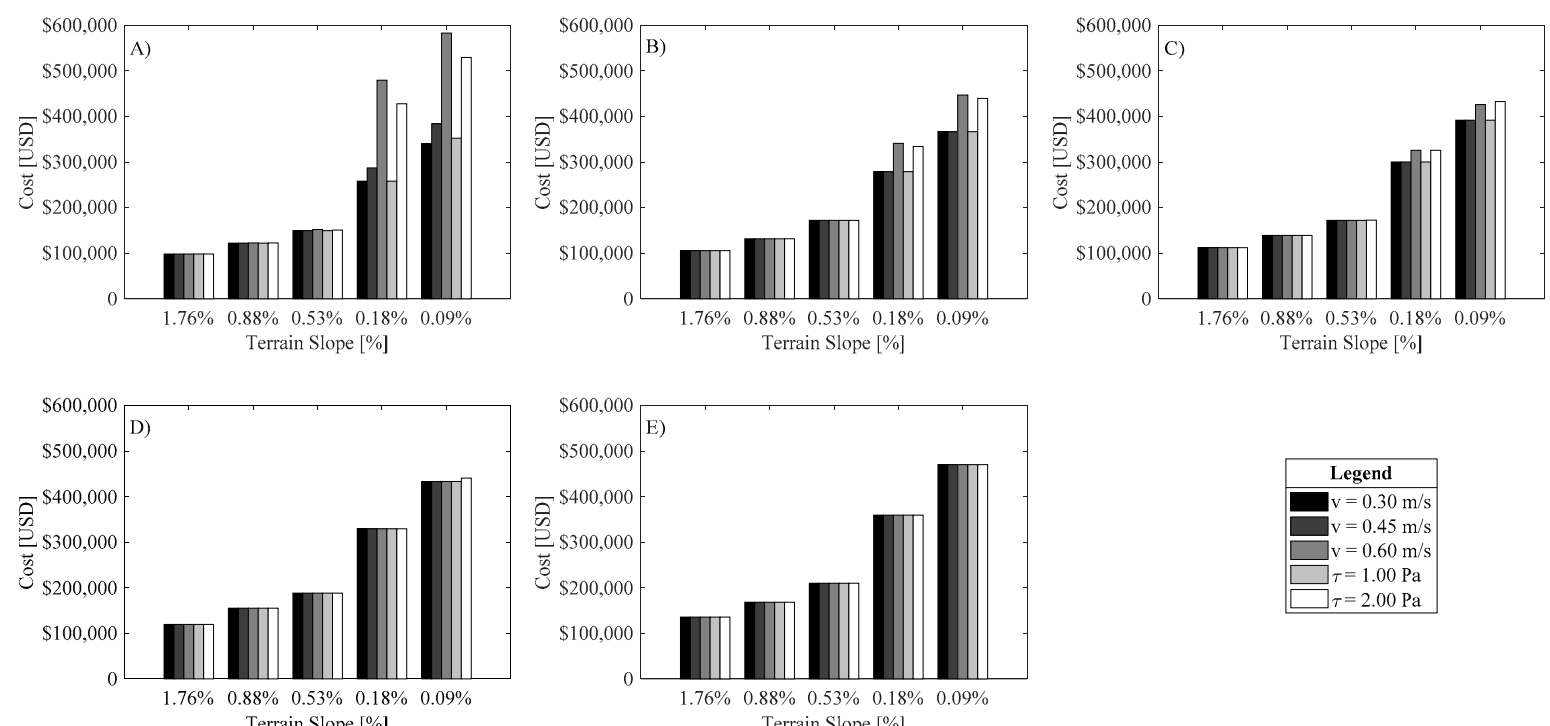

Figure 3. Network costs for the five wastewater proposed simulations: (A) Simulation 1 (Inflow per node $1 \mathrm{~L} / \mathrm{s}$ ), (B) Simulation 2 (Inflow per node $2 \mathrm{~L} / \mathrm{s}$ ), (C) Simulation 3 (Inflow per node $3 \mathrm{~L} / \mathrm{s}$ ), (D) Simulation 4 (Inflow per node $5 \mathrm{~L} / \mathrm{s}$ ), and (E) Simulation 5 (Inflow per node $10 \mathrm{~L} / \mathrm{s}$ ). Cost in (USD).

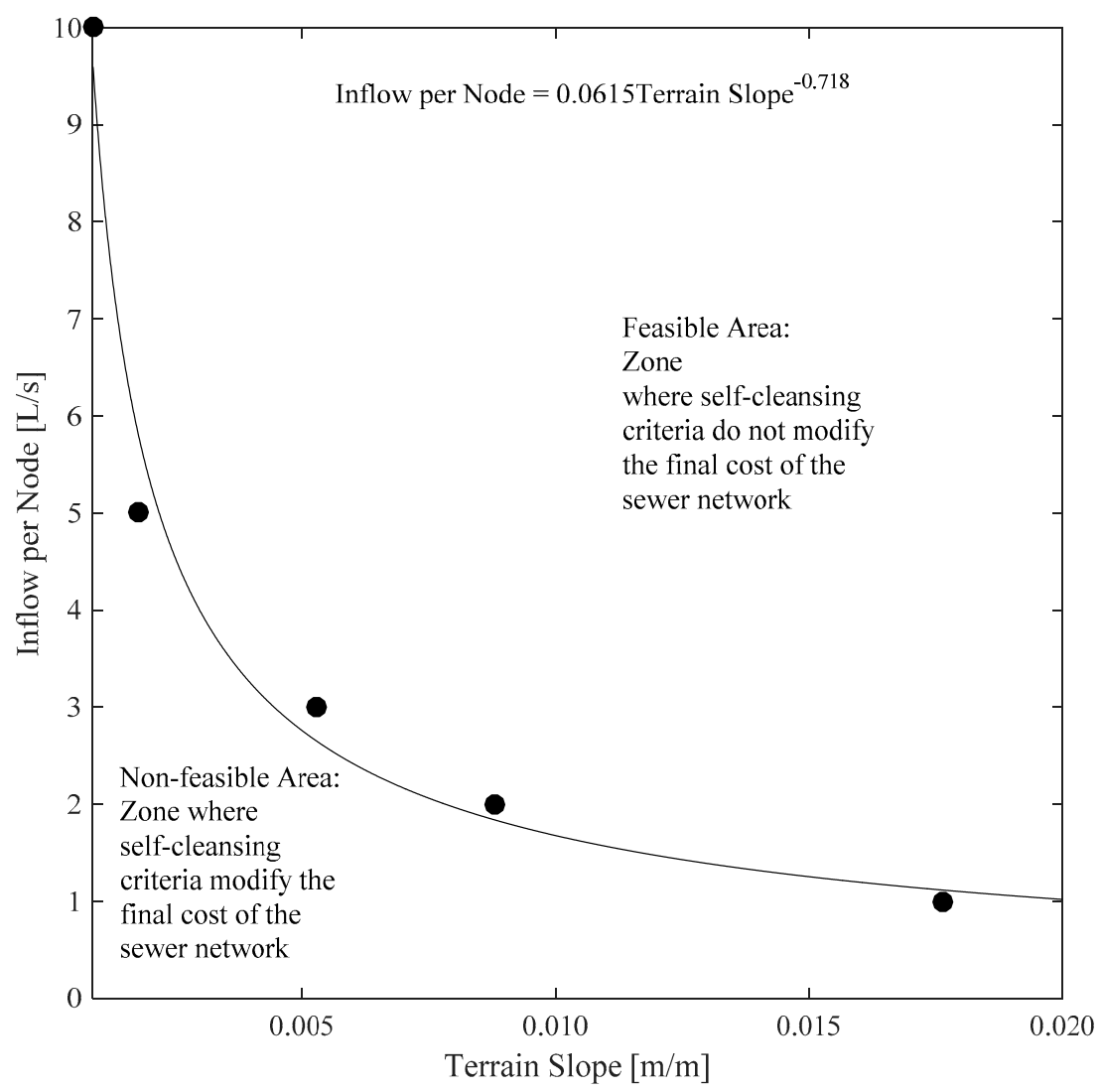

Figure 4. Self-cleansing limits in sewer systems. 
Figure 4 shows the region where the self-cleansing criteria should be taken into account in the design for future sewer systems. For example, if the design of a new sewer network has an inflow rate per node greater than of $3.0 \mathrm{~L} / \mathrm{s}$ and an average terrain slope of 0.01 , the network will always satisfy all the self-cleansing restrictions, and the final cost will not depend on the criterion used. However, if the network has the same inflow rate and an average terrain slope of 0.001 , the final cost changes and this change would depend on the self-cleansing restriction used. This figure is useful for a preliminary evaluation of the impact of self-cleansing criteria on future sewer systems designs. As shown in Figure 4, pipes located above the dotted line will always have velocities and shear stress values greater than the minimum required by water utilities to prevent sediment deposition on sewer pipes, even the most difficult. On the other hand, if the pipes are below the dotted line, the final cost will be different if a highly restrictive criterion, such as $2.0 \mathrm{~Pa}$ or $0.6 \mathrm{~m} / \mathrm{s}$, is used.

\section{Conclusions}

The impact of choosing self-cleansing criteria on the optimal design of sewer networks is presented in this paper. The impact evaluation of these criteria is carried out using an optimal sewer network design methodology by Duque et al. [12], subject to a number of design constraints. Three sewer networks were designed using this methodology taking into consideration several different self-cleansing criteria based on both minimum flow velocities and shear stresses.

The results obtained demonstrate that the influence of self-cleansing criteria on sewer systems optimal design depends mainly on the relationship between the land topography and the inflow (i.e., design) rate at each node of the network.

More specifically, the results obtained demonstrate that stormwater sewer system designs (case studies Mini-Chicó network and Mays and Wenzel [13] network) are not affected by the self-cleansing criteria. The reason for this, is that flow rates in these networks are high during precipitation events, resulting in velocities and shear stresses above the minimums required, regardless of the self-cleansing criteria used. In contrast, in wastewater sewer systems where the design flow rates are lower, self-cleansing criteria becomes relevant for the optimal network design.

Sewer networks with flat topography are also affected by the self-cleansing criteria used for their design. By applying a highly restrictive self-cleansing criterion, the cost of the network will be higher compared to a less restrictive criterion. In addition, in sewer pipes with design flow and terrain slopes greater than $10 \mathrm{~L} / \mathrm{s}$ and $0.09 \%$, respectively, the design will remain the same since self-cleansing restrictions do not affect the final design cost.

A graph depicting self-cleansing limits in sewer systems is presented in the paper (see Figure 4). This graph is useful for evaluating new sewer network designs. The designer must include the information for each pipe in the network (as a point in this graph), to determine if the self-cleansing restrictions should be considered in the optimal design or not. This is especially important in low-income areas because by using the graph in Figure 4 it is possible to determine if the construction of a gravity-based system is viable.

Finally, traditional self-cleansing criteria consider the variability of inflow at each node, i.e., non-steady flow conditions. Using the design flow rate, the self-cleansing conditions must be satisfied for the design flow. During lower flow rates, it is possible that particles deposit at the bottom of the pipes, however, when the design flow is reached all particles deposited are flushed and the pipe is cleaned. Therefore, the conclusions of this paper will be the same if other design flow rates are considered.

For future work, it is recommended that the proposed methodology be extended to larger sewer networks and take into account different cost models. Additionally, this extension should be applied in the estimation of the layout of the network, i.e., the flow directions and the initial nodes, which have the most influence on the optimal design of the sewers. 
Supplementary Materials: The following are available online at http://www.mdpi.com/2073-4441/11/6/1148/s1, Table S1: Data for Mini-Chicó sewer network, Table S2. Data for Mays and Wenzel [13] network, Table S3. Data for 'Kerman' city network. Taken from Afshar et al. [34], Table S4. First simulation scenario for the sensitivity analysis, Table S5. Second simulation scenario for the sensitivity analysis, Table S6. Third simulation scenario for the sensitivity analysis, Table S7. Fourth simulation scenario for the sensitivity analysis, Table S8. Fifth simulation scenario for the sensitivity analysis.

Author Contributions: Conceptualization, C.M., Z.K. and J.S.; Methodology, C.M. and J.S.; Software, C.M.; Validation, J.S. and Z.K.; Formal Analysis, C.M., Z.K. and J.S.; Investigation, C.M. and J.S.; Resources, J.S.; Data Curation, C.M.; Writing-Original Draft Preparation, C.M.; Writing-Review \& Editing, C.M., Z.K. and J.S.; Visualization, C.M.; Supervision, Z.K. and J.S.; Project Administration, J.S.; Funding Acquisition, No Funding Acquisition.

Funding: This research received no external funding.

Conflicts of Interest: The authors declare no conflict of interest.

\section{References}

1. Argaman, Y.; Shamir, U.; Spivak, E. Design of Optimal Sewerage Systems. J. Environ. Eng. Div. 1973, 99, 703-716.

2. Mein, W. Design of Sanitary Sewer Systems by Dynamic Programming. Master's Thesis, McMaster University, Hamilton, ON, Canada, 1975.

3. Li, G.; Matthew, R. New Approach for Optimization of Urban Drainage Systems. J. Environ. Eng. 1990, 116, 927-944. [CrossRef]

4. Holland, M. Computer Models of Wastewater Collection Systems. Master's Thesis, Harvard University, Cambridge, MA, USA, 1966.

5. Elimam, A.A.; Charalambous, C.; Ghobrial, F.H. Optimum Design of Large Sewer Networks. J. Environ. Eng. 1989, 115, 1171-1190. [CrossRef]

6. Walters, G.; Lohbeck, T. Optimal Layout of Tree Networks Using Genetic Algorithms. Eng. Optim. 1993, 22, 27-48. [CrossRef]

7. Afshar, M. Application of a Genetic Algorithm to Storm Sewer Network Optimization. Sci. Iran. 2006, 13, 234-244.

8. Cisty, M. Hybrid Genetic Algorithm and Linear Programming Method for Least-Cost Design of Water Distribution Systems. Water Resour. Manag. 2010, 24, 1-24. [CrossRef]

9. Cozzolino, L.; Cimorelli, L.; Covelli, C.; Mucherino, C.; Pianese, D. An Innovative Approach for Drainage Network Sizing. Water 2015, 7, 546-567. [CrossRef]

10. Hassan, W.; Jassem, M.; Mohammed, S. A GA-HP Model for the Optimal Design of Sewer Networks. Water Resour. Manag. 2018, 32, 865-879. [CrossRef]

11. Shao, Z.; Zhang, X.; Li, S.; Deng, S.; Chai, H. A Novel SWMM Based Algorithm Application to Storm Sewer Network Design. Water 2017, 9, 747. [CrossRef]

12. Duque, N.; Duque, D.; Saldarriaga, J. A New Methodology for the Optimal Design of Series of Pipes in Sewer Systems. J. Hydroinformatics 2016, 18, 757-772. [CrossRef]

13. Mays, L.W.; Wenzel, H.G. Optimal Design of Multilevel Branching Sewer Systems. Water Resour. Res. 1976, 12, 913-917. [CrossRef]

14. Ebtehaj, I.; Bonakdari, H.; Sharifi, A. Design Criteria for Sediment Transport in Sewers Based on Self-Cleansing Concept. J. Zhejiang Univ. Sci. A 2014, 15, 914-924. [CrossRef]

15. ATV-DVWK-Regelwerk. Hydraulische Dimensionierung Und Leistungsnachweis von Abwasserkanalen Und-Leitungen; AVT-DVWK-A 110; Gesellschaft zur Förderung der Abwassertechnik e.V. (GFA): Hennef, Germany, 2001.

16. Vongvisessomjai, N.; Tingsanchali, T.; Babel, M. Non-Deposition Design Criteria for Sewers with Part-Full Flow. Urban Water J. 2010, 7, 61-77. [CrossRef]

17. Montes, C.; Bohórquez, J.; Borda, S.; Saldarriaga, J. Criteria of Minimum Shear Stress vs. Minimum Velocity for Self-Cleaning Sewer Pipes Design. Procedia Eng. 2017, 186, 69-75. [CrossRef]

18. Lysne, D. Hydraulic Design of Self-Cleaning Sewage Tunnels. J. Sanit. Eng. Div. Am. Soc. Civ. Eng. 1969, 95, $17-36$. 
19. American Society of Civil Engineers (ASCE). Water pollution control federation. Design and Construction of Sanitary and Storm Sewers. In American Society of Civil Engineers Manuals and Reports on Engineering Practices; ASCE: Reston, VA, USA, 1970.

20. Yao, K. Sewer Line Design Based on Critical Shear Stress. J. Environ. Eng. Div. 1974, 100, 507-520.

21. Minister of Interior. Instruction Technique Relative Aux Réseaux d'assainissement Des Agglomerations; Circulaire Interministerielle IT 77284 I; Minister of Interior: Paris, France, 1977.

22. British Standard Institution. Sewerage-Guide to New Sewerage Construction BS8005 Part 1; British Standard Institution: London, UK, 1987.

23. Instituto Ecuatoriano de Normalización. CPE INEN 005-9-1 (1992): Código Ecuatoriano de La Construcción C.E.C. Normas Para Estudio y Diseño de Sistemas de Agua Potable y Disposición de Aguas Residuales Para Poblaciones Mayores a 1000 Habitantes; INEN: Quito, Ecuador, 1992.

24. European Standard EN 752-4. Drain and Sewer System Outside Building: Part 4. Hydraulic Design and Environmental Considerations; European Comitte for Standardization (CEN): Brussels, Belgium, 1997.

25. Great Lakes. Recommended Standars for Wastewater Facilities; Health Education Services Division, Health Research Inc.: Menands, NY, USA, 2004.

26. Comisión Nacional del Agua. Manual de Agua Potable, Alcantarillado y Saneamiento; Comisión Nacional del Agua: Coyoacán, México, 2007.

27. Instituto Boliviano de Normalización y Calidad. Diseño de Sistemas de Alcantarillado Sanitario y Pluvial (NB 688); Instituto Boliviano de Normalización y Calidad: La Paz, Bolivia, 2007.

28. Empresas Públicas de Medellín. Guía Para El Diseño Hidráulico de Redes de Alcantarillado; Empresas Públicas de Medellín: Medellín, Colombia, 2009.

29. Colombia, Ministerio de Vivienda, Ciudad y Territorio. Reglamento Técnico Del Sector de Agua Potable y Saneamiento Básico: TÍTULO D. Sistemas de Recolección y Evacuación de Aguas Residuales Domésticas y Aguas Lluvias; Colombia, Ministerio de Vivienda, Ciudad y Territorio: Bogotá, Colombia, 2012.

30. Bellman, R. On a Routing Problem. Q. Appl. Math. 1958, 16, 87-90. [CrossRef]

31. Maurer, M.; Scheidegger, A.; Herlyn, A. Quantifying Costs and Lengths of Urban Drainage Systems with a Simple Static Sewer Infrastructure Model. Urban Water J. 2013, 10, 268-280. [CrossRef]

32. Moeini, R.; Afshar, M. Sewer Network Design Optimization Problem Using Ant Colony Optimization Algorithm and Tree Growing Algorithm. In Proceedings of the EVOLVE-A Bridge between Probability, Set Oriented Numerics, and Evolutionary Computation IV, Leiden, The Netherlands, 10-13 July 2013.

33. Marchionni, V.; Lopes, N.; Mamouros, L.; Covas, D. Modelling Sewer Systems Costs with Multiple Linear Regression. Water Resour. Manag. 2014, 28, 4415-4431. [CrossRef]

34. Afshar, M.; Shahidi, M.; Rohani, M.; Sargolzaei, M. Application of Cellular Automata to Sewer Network Optimization Problems. Sci. Iran. 2011, 18, 304-312. [CrossRef] 